\title{
Concentration Dependence of Viscoelastic Properties of a Mixture of Three- and Four-Branched Star Polystyrenes*
}

\author{
Toshiro Masuda, Yasuhiko OHTA, Mitsunobu Kitamura, \\ Masahiko MINAMIDE, Kyoko KATO, and Shigeharu ONOGI \\ Department of Polymer Chemistry, Kyoto University, \\ Kyoto 606, Japan.
}

(Received December 24, 1980)

\begin{abstract}
Viscoelastic properties of concentrated solutions of a mixture of three- and fourbranched polystyrenes were measured by means of a concentric cylinder type rheometer. The Vogel parameters, $\alpha_{\mathrm{f}}$ and $T_{0}$, were calculated from the temperature dependence of viscosity and the shift factor $a_{\mathrm{r}}$. From the frequency dependence of the storage shear modulus $G^{\prime}$ and the loss modulus $G^{\prime \prime}$, the characteristic parameters in the terminal zone such as zero-shear viscosity $\eta_{0}$ and steadystate compliance $J_{\mathrm{e}}^{0}$ were evaluated. The dependence of these parameters on concentration was compared with that of concentrated solutions of linear polystyrenes. The concentration dependence of $\eta_{0}$ for star polymers is very similar to that for linear ones. However, $J_{\mathrm{e}}{ }^{0}$ for the mixture of threeand four-branched polystyrenes showed unusual behavior that was quite different from that of linear polymer and monodisperse star polymer. The entanglement compliance is also discussed.

KEY WORDS Viscoelasticity / Polystyrene / Branched Polymer / Viscosity /

Steady-State Compliance / Vogel Parameters / Concentration Dependence /
\end{abstract}

In our previous papers, the rheological properties in the rubbery and flow regions of concentrated solutions and melts of star-shaped polystyrene mixtures $^{1,2}$ and randomly branched polystyrenes ${ }^{3}$ were investigated. In these experiments, we noted the unusual behavior that the steady-state compliance $J_{\mathrm{e}}{ }^{0}$ of concentrated solutions of mixtures of threeand four-branched polystyrenes is much lower than those of the undiluted ones. ${ }^{1}$ Moreover, $J_{\mathrm{e}}{ }^{0}$ for $90 \mathrm{wt} \%$ solutions was independent of molecular weight, but that of $50 \mathrm{wt} \%$ solutions proportionally increased with molecular weight in the entanglement region. ${ }^{2}$ This behavior of $J_{\mathrm{e}}{ }^{0}$ observed for mixtures $^{2}$ is quite different from that for linear polymers $^{4-9}$ and also from star-shaped polymers with no distribution in the number and length of branches. ${ }^{10-17}$

In the present paper, the dynamic viscoelastic properties for concentrated solutions of mixtures of three- and four-branched star polystyrenes have been measured to determine the concentration dependence of parameters ${ }^{5}$ such as the Vogel tempera- ture $T_{0}$, temperature coefficient of free volume $\alpha_{\mathrm{f}}$, zero-shear viscosity $\eta_{0}$, and steady-state compliance $J_{\mathrm{e}}{ }^{0}$. The experimental results were compared with those for concentrated solutions of linear polystyrenes. ${ }^{9,17}$

\section{EXPERIMENTAL}

\section{Materials}

One (LB17) of the star-shaped polystyrene samples used in a previous study, ${ }^{1}$ which was a mixture of three- and four-branched polymers, was taken for this study. The preparative procedure of this star polystyrene is the same as that described before ${ }^{1,2}$ and was not repeated. The gel permeation chromatograms and the sedimentation patterns of this sample were also similar to those reported in the previous paper. ${ }^{2}$ For comparison, a narrow-distribution linear polystyrene sample L50 was also examined. ${ }^{17}$ The weight- and number-average molecular weights, $M_{w} / M_{n}$, and the coupling ratio $P$ (the ratio of $M_{n}$ of the star polymer to that of the corresponding branch) 
Table I. Molecular weights, molecular-weight distribution and coupling ratio (the average number of branches in a molecule) of the star and linear polystyrenes

\begin{tabular}{ccccc}
\hline \multirow{2}{*}{ Sample } & $M_{n} \times 10^{-5}$ & & & \\
\cline { 2 - 3 } & os & $M_{w} / M_{n}$ & $M_{w} \times 10^{-5}$ & $P$ \\
\hline LB17 & 3.51 & 1.16 & 4.07 & $\begin{array}{c}3.58 \\
\text { L50 }\end{array}$ \\
\hline
\end{tabular}

a Coupling ratio is 2.00 for linear polymer.

for these samples are tabulated in Table I.

Solutions of LB17 (BC 1 series) and L50 (SC 2 series) with polymer weight fractions of $0.07,0.10$, $0.20,0.30,0.50$, and $0.70 \mathrm{~g} \mathrm{~g}^{-1}$ were prepared and subjected to viscoelastic measurements.. As the solvent, Kaneclor 500 (KC5) a partially chlorinated biphenyl was used. The volume concentrations of these solutions were $0.104,0.147,0.284,0.412$, 0.641 , and $0.832 \mathrm{~g} \mathrm{ml}^{-1}$ at $50^{\circ} \mathrm{C}$, respectively.

\section{Measurements of Viscoelasticity}

The viscoelastic functions such as the storage shear modulus $G^{\prime}$ and loss modulus $G^{\prime \prime}$ of sample solutions were measured by means of the concentric cylinder type rheometer described in the previous papers. ${ }^{1-8}$ The measuring frequency ranged from
$4 \times 10^{-3}$ to $0.5 \mathrm{~Hz}$, and the temperature, from 5 to $150^{\circ} \mathrm{C}$. Frequency dependence curves of $G^{\prime}$ and $G^{\prime \prime}$ at various concentrations were superposed into a master curve at a certain temperature $T_{\mathrm{r}}$ and then it was reduced to $T_{\mathrm{r}}{ }^{\prime}$ at which each solution was in an iso-free-volume state; the fractional free volume $f$ was 0.0608 . This value of $f$ was obtained for the narrow-distribution linear polystyrenes in the molten state at $160^{\circ} \mathrm{C} .^{5}$

\section{RESULTS AND DISCUSSION}

\section{Frequency Dependences of Viscoelastic Functions}

As is well-known, the viscoelastic properties of polymer liquids depend not only on molecular weight and concentration but also on the segmental friction factor, ${ }^{18,19}$ which in turn depends strongly on concentration and temperature. Therefore, the concentration dependence of rheological properties of concentrated solutions should be compared at an iso-free-volume.

In Figures 1 and 2, the master curves of $G^{\prime}$ and $G^{\prime \prime}$ for solutions of the star-shaped polystyrene mixture (LB17) in the iso-free-volume state $(f=0.0608)$ are shown. In these two figures, the notation $\mathrm{BCl} 107$, for example, represents $7 \mathrm{wt} \%$ solution of LB17 in KC5. The abscissas of the figures are the reduced angular frequency $\omega a_{\mathrm{T}}$. The reference temperature $T_{\mathrm{r}}{ }^{\prime}$ corresponding to the iso-

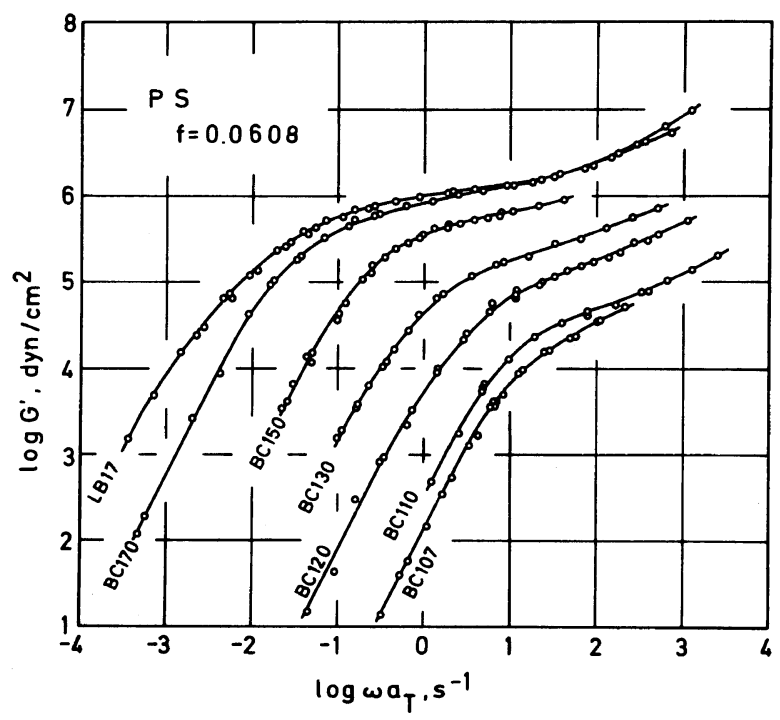

Figure 1. Master curves of $G^{\prime}$ for solutions of star-shaped polystyrene, LB17, reduced to the iso-freevolume state, $f=0.0608$. Corresponding temperature is $T_{\mathrm{r}}{ }^{\prime}$ shown in Table II for each solution. 


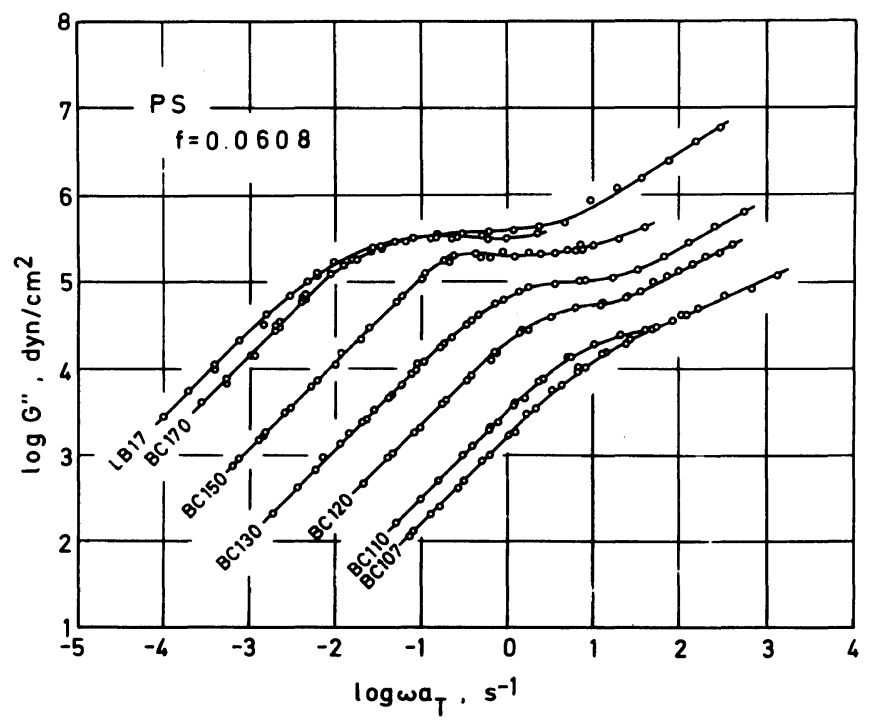

Figure 2. Master curves of $G^{\prime \prime}$ for solutions of star-shaped polystyrene, LB17, reduced to the iso-freevolume state, $f=0.0608$. Corresponding temperature is $T_{\mathrm{r}}{ }^{\prime}$ shown in Table II for each solution.

free-volume state for each solution is tabulated in Table II. The details of the temperature dependence of viscoelasticity will be discussed in the next section. As is evident from these figures, the long time end of each curve shifts to the higher frequency side and the rubbery plateau becomes lower, as the concentration decreases. The $G^{\prime}$ curves for solutions of high concentrations, including $\mathrm{BC} 130$ and $\mathrm{BC} 120$, show the rubbery plateau regions. This suggests that the critical concentration for entanglement coupling is about $w_{2}=0.2\left(0.284 \mathrm{~g} \mathrm{ml}^{-1}\right)$, where $w_{2}$ is the weight fraction of the polymer in solutions. Frequency dependence curves of $G^{\prime \prime}$ for samples at high concentrations show a maximum in the intermediate region between the terminal and rubbery zones. Such a maximum enables us to calculate the quasi-equilibrium modulus by the integration method. ${ }^{19}$ In the terminal zone, $\log G^{\prime}$ and $\log G^{\prime \prime} v s . \log \omega$ curves have the slopes of 2.0 and 1.0 , respectively. As the concentration decreases, the glass transition region (the high frequency end of each curve) shifts to the right.

\section{Shift Factor $a_{\mathrm{T}}$ and Effect of Temperature}

The shift factor $a_{\mathrm{T}}$ was obtained in applying the time-temperature superposition principle to the frequency dependence curves of $G^{\prime}$ and $G^{\prime \prime}$ for the BC 1 series. It was found that both the star and linear polymers give the same $a_{\mathrm{T}}$, which can be expressed by the following WLF type equation ${ }^{19}$ :

$$
\log a_{\mathrm{T}}=\frac{-c_{1}{ }^{\mathrm{r}}\left(T-T_{\mathrm{r}}\right)}{{c_{2}}^{\mathrm{r}}+\left(T-T_{\mathrm{r}}\right)}
$$

where $c_{1}{ }^{\mathrm{r}}=1 / 2.303 f_{\mathrm{r}}, c_{2}{ }^{\mathrm{r}}=f_{\mathrm{r}} / \alpha_{\mathrm{f}}, T_{\mathrm{r}}$ the reference temperature, $f_{\mathrm{r}}$ the fractional free volume at $T_{\mathrm{r}}$, and $\alpha_{\mathrm{f}}$ the temperature coefficient of the fractional free volume $f$ which is written as

$$
f=\alpha_{\mathrm{f}}\left(T-T_{0}\right)=f_{\mathrm{r}}+\alpha_{\mathrm{f}}\left(T-T_{\mathrm{r}}\right)
$$

The plot of $-\left(T-T_{\mathrm{r}}\right) / \log a_{\mathrm{T}}$ against $\left(T-T_{\mathrm{r}}\right)$ for each sample could be represented by a straight line, and the slope $(m)$ and intercept $(i)$ were used to evaluate the Vogel temperature $T_{0}$ and $\alpha_{\mathrm{f}}$ defined in the free-volume theory, ${ }^{18,19}$ according to the relations,

$$
\begin{gathered}
T_{0}=T_{\mathrm{r}}-i / m \\
\alpha_{\mathrm{f}}=m^{2} / 2.303 i
\end{gathered}
$$

The free volume parameters calculated at $T_{\mathrm{r}}=50^{\circ} \mathrm{C}$ are tabulated in Table II. Among these parameters, $c_{1}{ }^{\mathrm{r}}$ and $c_{2}{ }^{\mathrm{r}}$ depend on $T_{\mathrm{r}}$ but $\alpha_{\mathrm{f}}$ and $T_{0}$ do not. $T_{\mathrm{r}}{ }^{\prime}$ is the temperature at which each solution has the fractional free volume of 0.0608 , the value for the undiluted polymer at $160^{\circ} \mathrm{C}$.

The concentration dependences of $T_{\mathrm{r}}{ }^{\prime}, T_{0}$, and $\alpha_{\mathrm{f}}$ 
Table II. The WLF constants $\left(c_{1}{ }^{\mathrm{r}}\right.$ and $\left.c_{2}{ }^{\mathrm{r}}\right)$, the Vogel parameters $\left(\alpha_{\mathrm{f}}\right.$ and $\left.T_{0}\right)$, and the temperture $T_{\mathrm{r}}{ }^{\prime}$, corresponding to $f=0.0608$ for undiluted polystyrenes (LB17 and L50) and their solutions (BC1 and SC2 series). Linear and branched polystyrenes give the same data for free volume parameters

\begin{tabular}{|c|c|c|c|c|c|c|}
\hline \multirow{2}{*}{$w_{2}$} & $T_{\mathrm{r}}$ & \multirow{2}{*}{$c_{1}{ }^{\mathrm{r}}$} & \multirow{2}{*}{$c_{2}{ }^{r}$} & \multirow{2}{*}{$\alpha_{\mathrm{f}} \times 10^{4}$} & \multirow{2}{*}{$\frac{T_{0}}{{ }^{\circ} \mathrm{C}}$} & \multirow{2}{*}{$\frac{T_{\mathrm{r}}{ }^{\prime}}{{ }^{\circ} \mathrm{C}}$} \\
\hline & ${ }^{\circ} \mathrm{C}$ & & & & & \\
\hline 1.00 & - & - & - & 5.42 & 47.9 & 160.0 \\
\hline $0.90^{\mathrm{a}}$ & 50 & 26.92 & 28.0 & 5.76 & 22.0 & 127.6 \\
\hline 0.70 & 50 & 12.98 & 65.2 & 5.21 & -14.2 & 102.5 \\
\hline 0.50 & 50 & 9.09 & 91.5 & 5.22 & -41.5 & 74.7 \\
\hline 0.30 & 50 & 7.50 & 103.2 & 5.61 & -53.2 & 55.2 \\
\hline 0.20 & 50 & 6.84 & 103.4 & 6.14 & -53.5 & 45.6 \\
\hline 0.10 & 50 & 6.06 & 99.0 & 7.23 & -49.1 & 35.0 \\
\hline 0.07 & 50 & 5.45 & 105.8 & 7.53 & -55.9 & 24.8 \\
\hline $0.00^{\mathrm{b}}$ & 50 & 3.52 & 7.96 & 15.5 & -29.6 & 9.6 \\
\hline
\end{tabular}

a Values obtained in the preceding paper. ${ }^{2}$

b KC5 (solvent).

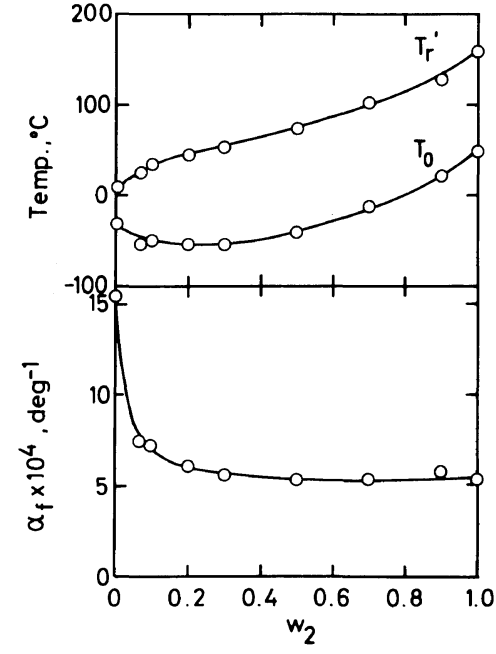

Figure 3. $T_{\mathrm{r}}{ }^{\prime}, T_{0}$, and $\alpha_{\mathrm{f}}$ plotted against weight fraction of polymer in solution for undiluted star polystyrene (LB17), its solutions (BC 1 series) and the solvent.

for LB17, shown in Figure 3, indicate that $T_{\mathrm{r}}{ }^{\prime}$ and $T_{0}$ decrease with decreasing concentration at high concentrations and $T_{0}$ increases at low concentrations after passing through a minimum. $\alpha_{\mathrm{f}}$ is almost constant at $w_{2}$ from 1.0 to 0.2. At lower concentrations, however, $\alpha_{\mathrm{f}}$ increases sharply with decreasing $w_{2}$ and reaches the solvent value. This result is quite similar to that obtained for PMMA previously $^{8}$

Concentration Dependence of Zero-Shear Viscosity

The concentration dependence of zero-shear viscosity $\eta_{0}$,

$$
\eta_{0}=\lim _{\omega \rightarrow 0} G^{\prime \prime} / \omega
$$

for solutions of the star polymer ( $\mathrm{BC} 1$ series) is shown in Figure 4. In this figure, the closed and open circles represent zero-shear viscosities for solutions at a constant temperature, $T=50^{\circ} \mathrm{C}$, and in the iso-free-volume state, $f=0.0608$, respectively. The concentration $c$ in $\mathrm{g} \mathrm{ml}^{-1}$ was employed as the abscissa.

As evident from Figure 4, the concentration dependence of $\eta_{0}$ at $50^{\circ} \mathrm{C}$ (closed circles) can be represented by a smooth curve. The viscosity and the slope of the curve at high concentration are very high since the free volumes are small; for example, $\eta_{0}$ is proportional to $c^{40}$ at $c=0.832 \mathrm{~g} \mathrm{ml}^{-1} \cdot \eta_{0}$ in the iso-free-volume state $(f=0.0608)$ shown by open circles, however, is much less dependent on the concentration.

The concentration dependence of $\eta_{0}$ in the isofree-volume state for the star polymer (LB17; open circles) is compared with that for the linear polymer (L50; closed circles) in Figure 5. The concentration dependence of $\eta_{0}$ for the linear polystyrenes can be represented by two straight lines having slopes of 


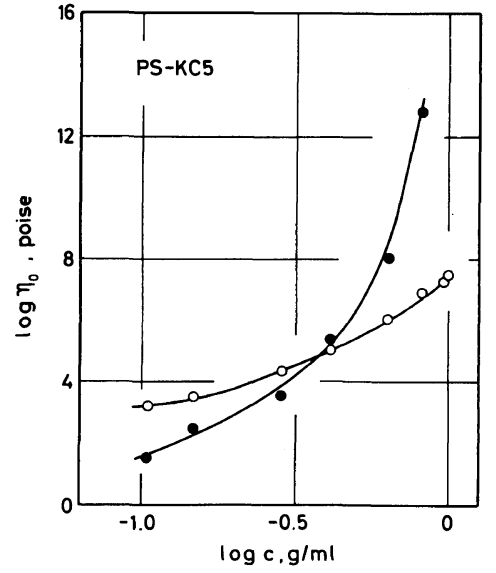

Figure 4. Concentration dependence of zero-shear viscosity $\eta_{0}$ for star-shaped polystyrene solutions in $\mathrm{KC} 5$ at $50^{\circ} \mathrm{C}$ (closed circles) and in an iso-free-volume state at $f=0.0608$ (open circles).

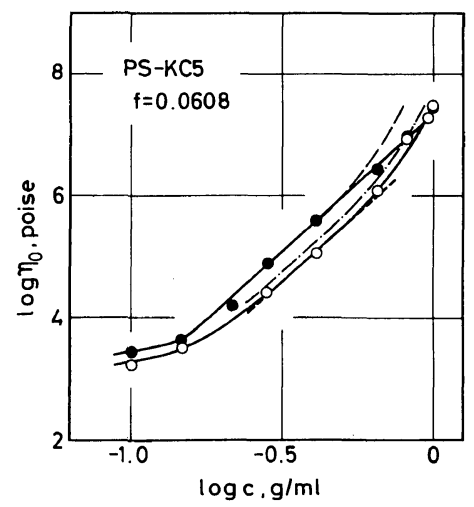

Figure 5. Concentration dependence of zero-shear viscosity $\eta_{0}$ for solutions of star polystyrene, LB17 (open circles) and linear polystyrene, L50 (closed circles) reduced to the iso-free-volume state at $f=0.0608$. The broken (--) and chain (-- - ) lines represent the relations between $\eta_{0}$ vs. $c\left(2 M_{w} / P M_{\mathrm{L}}\right)^{0.78}$ and $\eta_{0} v s$. $c\left(g_{\mathrm{s}}^{2} M_{w} / M_{\mathrm{L}}\right)^{0.78}$, respectively.

4.5 and unity in the high and low concentration ranges, respectively. On the other hand, $\eta_{0}$ for the branched samples exhibits three regions in the concentration dependence; $\eta_{0} \propto c^{1}\left(c<0.18 \mathrm{~g} \mathrm{ml}^{-1}\right)$, $\eta_{0} \propto c^{4.5} \quad(0.18<c<0.53)$ and $\eta_{0} \propto c^{>4.5} \quad(c>0.53)$. Thus, the star polymer shows a stronger concentration dependence of $\eta_{0}$ at high concentrations than the linear polymer does. The dependences of $\eta_{0}$ on concentration and molecular weight are represented by, ${ }^{20,21}$

$$
\eta_{0} \propto c c^{\alpha} M_{w}{ }^{\beta}
$$

With $\alpha=4.5, \beta=3.5$ for linear and branched systems, the ratios $\beta / \alpha$ is calculated to be 0.78 . This value is the same as or near that $(0.78$ or 0.85$)$ reported recently. ${ }^{17,22}$ Marin et al. ${ }^{22}$ proposed a plot of $\eta_{0}$ against $c\left(g_{\mathrm{s}}^{2} M\right)^{\beta / \alpha}$, which gives a single curve for the concentration dependence of $\eta_{0}$ for three- and four-branched polybutadienes as well as for the linear one. The plot of $\eta_{0}$ against $c\left(g_{\mathrm{s}}^{2} M_{w} / M_{\mathrm{L}}\right)^{0.78}$, which is equivalent to this plot, is shown by dot-dash line in Figure 5. $M_{\mathrm{L}}$ is the molecular weight of the linear polymer L50, $2.98 \times 10^{5}$, and $g_{\mathrm{s}}^{2}$ was calculated by substituting $P=3.58$ into the following equation, ${ }^{2}$

$$
g_{\mathrm{s}}{ }^{2}=\frac{3 P-2}{P^{2}}
$$

The broken line in this figure represents the relation between $\eta_{0}$ and $c\left(2 M_{w} / P M_{\mathrm{L}}\right)^{0.78} . P$ is the average number of branches in a molcule. $(2 / P)$ seems to be better than $g_{\mathrm{s}}^{2}$ for reduction of the concentration dependence of $\eta_{0}$ of the mixture of star polystyrenes.

\section{Concentration Dependence of Steady-State Com- pliance}

Elastic properties of polymer liquids in the flow region are characterized by the steady-state compliance $J_{\mathrm{e}}{ }^{0}$ defined by,

$$
J_{\mathrm{e}}^{0}=\lim _{\omega \rightarrow 0} \frac{G^{\prime}(\omega)}{G^{\prime 2}(\omega)+G^{\prime 2}(\omega)}
$$

The concentration dependence of $J_{\mathrm{e}}^{0}$ for the star (LB17; open circles) and linear (L50; closed circles) polystyrenes at $50^{\circ} \mathrm{C}$ is shown in Figure 6. These values of $J_{\mathrm{e}}{ }^{0}$ were computed by multiplying those in the iso-free-volume state $\left(\right.$ at $\left.T_{\mathrm{r}}{ }^{\prime}\right)$ by $\left(273+T_{\mathrm{r}}{ }^{\prime}\right) \rho /$ $(173+50) \rho_{0}$, where $\rho$ and $\rho_{0}$ are densities of the solutions at $T_{\mathrm{r}}^{\prime}$ and $50^{\circ} \mathrm{C}$. The square mark in this figure indicates the value estimated by interpolation of the molecular weight dependence of $J_{\mathrm{e}}{ }^{0}$ for $0.255 \mathrm{~g} \mathrm{ml}^{-1}$ solutions of four-branched star polystyrenes reported by Utracki and Roovers. ${ }^{10}$

As is seen from Figure $6, J_{\mathrm{e}}^{0}$ for the linear polymers (L50) is proportional to $c^{-2}$ at high concentrations and to $c^{-1}$ at low concentrations. $J_{\mathrm{e}}{ }^{0}$ for branched polymers (LB17) is also proportional to $c^{-2}$ and $c^{-1}$ at higher and lower concentrations, 


\section{T. MASUdA et al.}

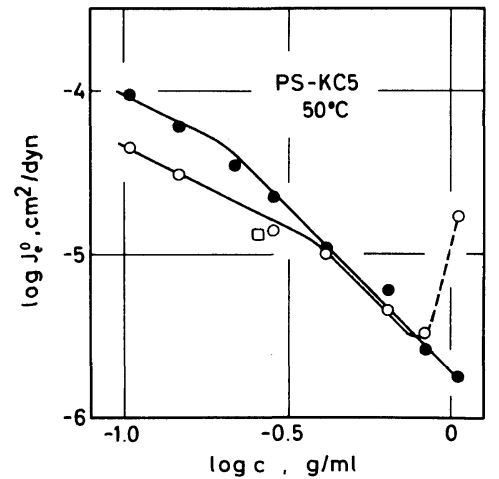

Figure 6. Concentration dependence of steady-state compliance $J_{\mathrm{e}}{ }^{0}$ for solutions of star-shaped polystyrene, LB17 (open circles) and linear polystyrene, L50 (closed circles). A square indicates the value of $J_{\mathrm{e}}{ }^{0}$ for 0.255 $\mathrm{g} \mathrm{ml}^{-1}$ solutions of four-branched polystyrene reported by Utracki and Roovers. ${ }^{10}$

respectively, except for extremely high concentrations where $J_{\mathrm{e}}{ }^{0}$ begins to increase abruptly with concentration. The value of $J_{\mathrm{e}}^{0}$ for the undiluted star polymer (the open circle to the extreme right) is about ten times as high as the extension of the straight line of $J_{\mathrm{e}}^{0} \propto c^{-2} . J_{\mathrm{e}}^{0}$ of undiluted linear polymers is always lower than that of the solutions. ${ }^{9}$ The value of $J_{\mathrm{e}}{ }^{0}$ obtained by extension of the straight line to the undiluted state agrees with that of $J_{\mathrm{e}}{ }^{0}$ for four-branched star polystyrenes with the same molecular weight reported by Graessley and Roovers ${ }^{12}$ and by Isono et al. ${ }^{14}$ Moreover, $J_{\mathrm{e}}{ }^{0}$ for the four-branched star polymer (square) ${ }^{10}$ is a little lower than, but very near the $\log J_{\mathrm{e}}{ }^{0} v s . \log c$ curve for the mixture of three- and four-branched polystyrenes. The behavior of $J_{e}^{0}$ for the mixture of star polymers shown in Figure 6 is quite different from that recently reported by Isono et al. ${ }^{15}$ Marin et al.,${ }^{22}$ and us, ${ }^{16}$ for monodisperse star polymers with a fixed number of branches: Isono et al. ${ }^{15}$ reported that $J_{\mathrm{e}}{ }^{0}$ for four-branched polystyrenes was proportional to $c^{-1}$ at concentrations lower than $0.5 \mathrm{~g} \mathrm{ml}^{-1}$ and that the linear relationship between $J_{\mathrm{e}}{ }^{0}$ and $c^{-1}$ may be extended to values for undiluted polymers. More recently, it has been reported for three- and four-branched polybutadienes ${ }^{22}$ and sixbranched polystyrene ${ }^{16}$ that $J_{\mathrm{e}}^{0}$ is inversely proportional to the concentration over a wide range of concentration including undiluted polymers.

On the other hand, the concentration dependence of the mixture of star polystyrenes which have a distribution in the number of branches, is quite different from that of the completely monodisperse star polymers mentioned above. In a recent investigation $^{15}$ on concentration dependence of $J_{\mathrm{e}}{ }^{0}$ for four-branched star and comb polystyrenes, the reduced compliances $J_{\mathrm{eR}}\left(\equiv J_{\mathrm{e}}{ }^{0} c R T / M\right)$ for these two types of branching were plotted against $c M$. The figure (Figure 6 in ref 15) shows that $\log J_{\mathrm{eR}} v s$. $\log (c M)$ relation has a horizontal part at low $c M$ and a slope of -1 at high $c M$. It also shows a hump in the intermediate region of $c M$. In spite of the hump, the authors concluded that the $J_{\mathrm{eR}}$ behavior of comb polymers is the same as that of linear and star polymers. We replotted the numerical data of $J_{\mathrm{e}}{ }^{0}$ given in the table of ref 15 against concentration and found that $J_{\mathrm{e}}^{0}$ depends very weakly on concentration for the comb polystyrene solutions; the slope of $\log J_{\mathrm{e}}^{0} v s . \log c$ is slightly negative and near. zero. This suggests that the $\log J_{\mathrm{eR}} v s . \log (c M)$ relation should have a slope close to plus unity, which has not been observed for linear polymers and star polymers with a fixed number of branches. This unusual behavior of $J_{\mathrm{e}}{ }^{0}$ observed for the mixture of three- and four-branched polystyrenes in this study and for comb-shaped polystyrenes mentioned above may be characteristic of branched polymers with distribution in number of branches. A similar weak concentration dependence of $J_{\mathrm{e}}{ }^{0}$ has also been observed for solutions of randomly branched polystyrenes. ${ }^{3}$ We also replotted the $J_{\mathrm{e}}{ }^{0}$ data for undiluted comb-shaped polystyrenes and their concentrated solutions against molecular weight. ${ }^{15}$ The results show that $J_{\mathrm{e}}{ }^{0}$ for concentrated solutions clearly depends on molecular weight $\left(J_{\mathrm{e}}^{0} \propto M^{\sim 1}\right)$ for any series of samples (with a constant number of branches and a constant molecular weight of branches), while $J_{\mathrm{e}}{ }^{0}$ for undiluted polymers is independent of molecular weight.

Zero-shear viscosity $\eta_{0}$ in the iso-free-volume state at $T_{\mathrm{r}}{ }^{\prime}$, steady-state compliance $J_{\mathrm{e}}{ }^{0}$ and isothermal viscosity $\eta_{0}^{50}$ at $50^{\circ} \mathrm{C}$ are tabulated in Table III for the undiluted star polystyrene LB17 and its solutions.

In Figure 7 the concentration dependence of $J_{\mathrm{e}}{ }^{0}$ for solutions of LB17 (open circles) is shown together with those for 50 and $90 \mathrm{wt} \%$ solutions of branched polymers of different molecular weight (closed circles) reported in a previous paper. ${ }^{2}$ The closed circle to the extreme right $(90 \mathrm{wt} \% ; 0.987$ $\mathrm{g} \mathrm{ml}^{-1}$ ) indicates that the experimental points for 
Rheological Properties of Anionic Polystyrenes. X.

Table III. Zero-shear viscosity $\left(\eta_{0}\right)$ at $T_{\mathrm{r}}{ }^{\prime}$ where $f=0.0608$, and steady-state compliance $\left(\eta_{\mathrm{e}}{ }^{0}\right)$ and iso-thermal viscosity $\left(\eta_{0}^{50}\right)$ at $50^{\circ} \mathrm{C}$ for undiluted star polystyrene LB17 amd its solutions

\begin{tabular}{|c|c|c|c|c|c|c|}
\hline \multirow{2}{*}{ Sample } & \multirow{2}{*}{$w_{2}$} & \multirow{2}{*}{$\frac{T_{\mathrm{r}}{ }^{\prime}}{{ }^{\circ} \mathrm{C}}$} & \multirow{2}{*}{$\frac{c \text { at } T_{\mathrm{r}}^{\prime}}{\mathrm{g} \mathrm{ml}^{-1}}$} & \multirow{2}{*}{$\begin{array}{c}\eta_{0} \\
\text { poises }\end{array}$} & \multirow{2}{*}{$\frac{J_{\mathrm{e}}^{0}}{\mathrm{~cm}^{2} \mathrm{dyn}^{-1}}$} & \multirow{2}{*}{$\frac{\eta_{0}^{50}}{\text { poises }}$} \\
\hline & & & & & & \\
\hline LB17 & 1.00 & 160.0 & 1.000 & $3.05 \times 10^{7}$ & $1.70 \times 10^{-5}$ & - \\
\hline a & 0.90 & 127.6 & 0.964 & $1.85 \times 10^{7}$ & $9.50 \times 10^{-6}$ & - \\
\hline $\mathrm{BC} 170$ & 0.70 & 102.5 & 0.822 & $9.0 \times 10^{6}$ & $3.3 \times 10^{-6}$ & $6.3 \times 10^{12}$ \\
\hline $\mathrm{BC} 150$ & 0.50 & 74.7 & 0.634 & $1.18 \times 10^{6}$ & $4.5 \times 10^{-6}$ & $1.10 \times 10^{8}$ \\
\hline $\mathrm{BC} 130$ & 0.30 & 55.2 & 0.411 & $1.16 \times 10^{5}$ & $1.01 \times 10^{-5}$ & $2.45 \times 10^{5}$ \\
\hline BC120 & 0.20 & 45.6 & 0.285 & $2.4 \times 10^{4}$ & $1.4 \times 10^{-5}$ & $3.7 \times 10^{3}$ \\
\hline $\mathrm{BC} 110$ & 0.10 & 35.0 & 0.148 & $3.15 \times 10^{3}$ & $3.10 \times 10^{-5}$ & $2.62 \times 10^{2}$ \\
\hline $\mathrm{BC} 107$ & 0.07 & 24.8 & 0.105 & $1.67 \times 10^{3}$ & $4.51 \times 10^{-5}$ & $3.25 \times 10$ \\
\hline
\end{tabular}

a Data in this row are for $90 \mathrm{wt} \%$ solutions of the same type of star polystyrenes. ${ }^{2} \eta_{0}$ is interpolated at the same molecular weight and $J_{\mathrm{e}}{ }^{0}$ is the average value for three samples of different molecular weight.

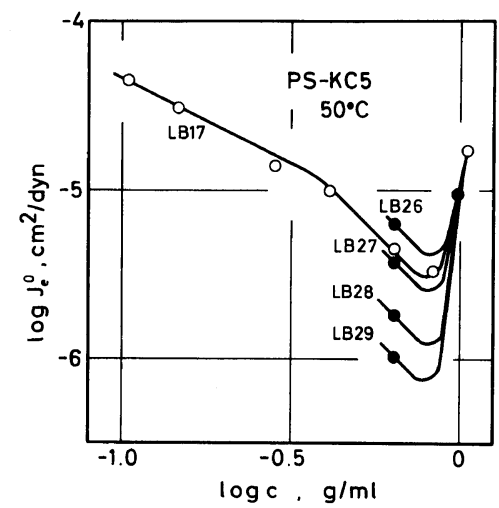

Figure 7. Concentration dependence of steady-state compliance $J_{\mathrm{e}}^{0}$ for solutions of star polystyrene, LB17. Closed circles indicate the data of 90 and $50 \mathrm{wt} \%$ solutions of star polystyrenes ${ }^{2}: M_{w}$ of these samples are 595,000 (LB26), 380,000 (LB27), 200,000 (LB28), and 113,000 (LB29).

three samples of different molecular weights coincide. ${ }^{2} J_{\mathrm{e}}{ }^{0}$ for $90 \mathrm{wt} \%$ solutions is lower than that for the undiluted polymer and higher than that for $50 \mathrm{wt} \%$ solutions irrespective of molecular weight.

Summarizing the experimental results obtained in this and previous studies, ${ }^{2}$ we can devide the concentration dependence of steady-state compliance $J_{\mathrm{e}}{ }^{0}$ for the mixture of star polymers each with a different number of branches into three types. At concentrations below $30 \mathrm{wt} \%, J_{\mathrm{e}}{ }^{0}$ is proportional to $c^{-1}$, and at concentrations between 30 and $70 \mathrm{wt} \%$, $J_{\mathrm{e}}{ }^{0}$ is proportional to $c^{-2}$. In those concentration regions, $J_{\mathrm{e}}{ }^{0}$ is proportional to molecular weight. At higher concentrations, $J_{\mathrm{e}}{ }^{0}$ increases rapidly after passing through a minimum at about $70 \mathrm{wt} \%$ and is independent of molecular weight.

\section{Viscoelastic Properties in the Rubbery Region}

As seen in Figure $1, G^{\prime}$ is not constant in the rubbery plateau. It is difficult to determine the entanglement modulus $G_{\mathrm{eN}}^{0}$ accurately from the height of the plateau. According to Sanders et al. ${ }^{19,24} G_{\mathrm{eN}}^{0}$ or the entanglement compliance $J_{\mathrm{eN}}^{0}$ can be evaluated by integration of $G^{\prime \prime}$ over the region of $\ln \omega$ encompassing the maximum of $G^{\prime \prime}$,

$$
G_{\mathrm{eN}}^{0}=1 / J_{\mathrm{eN}}^{0}=\frac{2}{\pi} \int_{-\infty}^{a} G^{\prime \prime} \mathrm{d} \ln \omega
$$

In practice, a $G^{\prime \prime} v s . \ln \omega$ curve is numerically integrated from $\ln \omega=-\infty$ to the maximum of $G^{\prime \prime}$, and the result is doubled. ${ }^{5}$ The relation between $J_{\mathrm{eN}}^{0}$ and $M_{\mathrm{e}}$ is given by

$$
J_{\mathrm{eN}}^{0}=\frac{M_{\mathrm{e}}}{g_{\mathrm{N}} c R T}
$$

where $g_{\mathrm{N}}$ is a front factor. This equation is analogous to the relation between the modulus and the average molecular weight between crosslinking point. The values of $J_{\mathrm{eN}}^{0}$ evaluated by eq 8 and those of $M_{\mathrm{e}}$ by eq 9 with $g_{\mathrm{N}}=1$ for the star polystyrenes are tabulated in Table IV. It is seen that $J_{\mathrm{eN}}^{0}$ and $M_{\mathrm{e}}$ decrease with increasing concentration.

In Figure 8, the concentration dependences of $J_{\mathrm{eN}}^{0}$ and $M_{\mathrm{e}}$ for the star polystyrene LB17 (open circles) 
Table IV. Entanglement compliance $\left(J_{\mathrm{eN}}^{0}\right)$ at $50^{\circ} \mathrm{C}$, converted from $J_{\text {eN }}^{0}$ in iso-free-volume state (at $\left.T_{\mathrm{r}}{ }^{\prime}\right)$ and average molecular weight between entanglement loci $\left(M_{\mathrm{e}}\right)$ calculated from eq $10 . M_{\mathrm{e}}$ is assumed to be independent of temperature

\begin{tabular}{|c|c|c|c|c|c|}
\hline & \multirow{2}{*}{ Sample } & \multirow{2}{*}{$w_{2}$} & \multirow{2}{*}{$\frac{c \text { at } 50^{\circ} \mathrm{C}}{\mathrm{g} \mathrm{ml}^{-1}}$} & \multirow{2}{*}{$\frac{J_{\mathrm{eN}}^{0} \text { at } 50^{\circ} \mathrm{C}}{\mathrm{cm}^{2} \mathrm{dyn}^{-1}}$} & \multirow{2}{*}{$M_{\mathrm{e}}$} \\
\hline & & & & & \\
\hline \multirow{5}{*}{ Star } & LB17 & 1.00 & 1.05 & $8.83 \times 10^{-7}$ & 24,900 \\
\hline & a & 0.90 & 0.987 & $9.47 \times 10^{-7}$ & 25,100 \\
\hline & $\mathrm{BC} 170$ & 0.70 & 0.832 & $9.36 \times 10^{-7}$ & 20,900 \\
\hline & $\mathrm{BC} 150$ & 0.50 & 0.641 & $2.02 \times 10^{-6}$ & 34,700 \\
\hline & BC130 & 0.30 & 0.412 & $4.07 \times 10^{-6}$ & 45,000 \\
\hline
\end{tabular}

a Data in this row are for $90 \mathrm{wt} \%$ solutions of the same type of polystyrenes. ${ }^{2} \quad J_{\mathrm{eN}}^{0}$ and $M_{\mathrm{e}}$ are average values of the three samples.

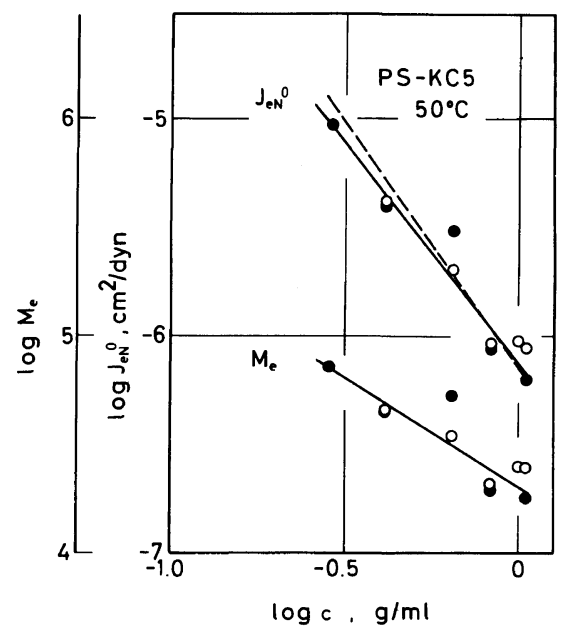

Figure 8. Concentration dependence of entanglement compliance $J_{\mathrm{eN}}^{0}$ and average molecular weight between entanglement loci, $M_{\mathrm{e}}$ for solutions of star-shaped, LB17 (open circles) and linear polystyrene, L50 (closed circles). The broken line has a slope of -2.24 .

and the linear polystyrene L50 (closed circles) are shown. It can be seen that $J_{\mathrm{eN}}^{0}$ is proportional to $c^{-2}$ and $M_{\mathrm{e}}$ is proportional to $c^{-1}$. Another dependence, $J_{\mathrm{eN}}^{0} \propto c^{-2.24}$ has been reported ${ }^{22}$ recently, it is difficult to determine which is more appropriate, the slope of -2.0 (upper solid line) or -2.24 (broken line). Both the linear and star polystyrenes show the same values and the same concentration dependence of $J_{\mathrm{eN}}^{0}$ and $M_{\mathrm{e}}$. The unusual behavior observed for $J_{\mathrm{e}}{ }^{0}$ at extremely high concentrations was not observed for $J_{\mathrm{eN}}^{0}$.
Acknowledgment. This work was supported in part by a Grant-in-Aid for Scientific Research from the Ministry of Education, Science and Culture of Japan (No. 443021).

\section{REFERENCES}

1. T. Masuda, Y. Ohta, and S. Onogi, Macromolecules, 4, 763 (1971).

2. Y. Ohta, M. Kitamura, T. Masuda, and S. Onogi, Polym. J., 13, 859 (1981).

3. T. Masuda, Y. Nakagawa, Y. Ohta, and S. Onogi, Polym. J., 3, 92 (1972).

4. S. Onogi, T. Masuda, and T. Ibaragi, Kolloid Z. Z. Polym., 222, 110 (1968).

5. S. Onogi, T. Masudà, and K. Kitagawa, Macromolecules, 3, 109 (1970).

6. T. Masuda, K. Kitagawa, T. Inoue, and S. Onogi, Macromolecules, 3, 116 (1970).

7. S. Onogi, T. Masuda, N. Toda, and K. Koga, Polym. J., 1, 542 (1970).

8. T. Masuda, N. Toda, Y. Aoto, and S. Onogi, Polym. J., 3, 315 (1972).

9. W. W. Graessley, Adv. Polym. Sci., 16, 1 (1974).

10. L. A. Utracki and J. E. L. Roovers, Macromolecules, 6, 373 (1973).

11. W. W. Graessley, T. Masuda, J. E. L. Roovers, and N. Hadjichristidis, Macromolecules, 9, 127 (1976).

12. H. Kajiura, Y. Ushiyama, T. Fujimoto, and $\mathbf{M}$. Nagasawa, Macromolecules, 11, 894 (1978).

13. W. W. Graessley and J. Roovers, Macromolecules, 12, 959 (1979).

14. Y. Isono, T. Fujimoto, H. Inagaki, M. Shishido, and M. Nagasawa, Polym. J., 12, 131 (1980).

15. Y. Isono, T. Fujimoto, H. Kajiura, and $\mathbf{M}$. Nagasawa, Polym. J., 12, 369 (1980).

16. T. Masuda, Y. Ohta, M. Kitamura, Y. Saito, K. Kato, and S. Onogi, Macromolecules, 14, 354 (1981). 
Rheological Properties of Anionic Polystyrenes. X.

17. Y. Ohta, Y. Saito, Y. Masuda, and S. Onogi, Macromolecules, 14, in press.

18. G. C. Berry and T. G. Fox, Adv. Polym. Sci., 5, 261 (1968).

19. J. D. Ferry, "Viscoelastic Properties of Polymers," 3rd ed, Wiley, New York, 1980.

20. S. Onogi, S. Kimura, T. Kato, T. Masuda, and N. Miyanaga, J. Polym. Sci., C, 15, 381 (1966).
21. S. Onogi, T. Masuda, N. Miyanaga, and Y. Kimura, J. Polym. Sci., A, 5, 899 (1967).

22. G. Marin, E. Menezes, V. R. Raju, and W. W. Graessley, Rheol. Acta, 19, 462 (1980).

23. B. H. Zimm and W. H. Stockmayer, J. Chem. Phys., 17, 1301 (1949).

24. J. F. Sanders, J. D. Ferry, and R. H. Valentine, J. Polym. Sci., A-2, 6, 967 (1968). 